\title{
Heat Stable Protein with Anticoagulant and Smooth Muscle Contractile Actions Isolated from Habu (Trimeresurus flavoviridis) Venom
}

\author{
Yoko ANIYA, *Matao SAKANASHI, *Katsuhiko NOGUCHI \\ and ** Kichihiko MATSUSAKI \\ Laboratory of Pharmacology and Toxicology. School of Health Sciences, \\ *Department of Pharmacology, School of Medicine, University of the Ryukyus, \\ Nishihara, Okinawa 903-01, Japan \\ **Miyazaki Medical College, Kiyotake, Miyazaki 889-16, Japan \\ Accepted August 14, 1985
}

\begin{abstract}
The biological activity of a Habu (Trimeresurus flavoiridis) venom fraction with drug-metabolizing enzyme inhibitory action was studied. The venom fraction, which was isolated through Sephadex G-100 gel filtration and cation exchange chromatography on Amberlite CG50, caused an increase of vascular permeability and hemorrhage, but these actions were lost after heating at $70^{\circ} \mathrm{C}$ for $5 \mathrm{~min}$. The fraction showed anticoagulant activity on citrated blood, and this activity remained after heating of the venom. Guinea pig ileum was contracted by treatment with nonheated or heated venom fraction, and these contractions were inhibited with atropine and potentiated with physostigmine. These results suggest that the drug-metabolizing enzyme inhibitor isolated from Habu venom involves the heat stable component with anticoagulant activity and smooth muscle contractile action.
\end{abstract}

Habu snake (Trimeresurus flavoviridis) venom inhibits hepatic microsomal drugmetabolizing enzymes under both in vitro and in vivo conditions, and the drugmetabolizing enzyme inhibitor has been isolated from the venom (1). This inhibitor is heat stable and is separated from phospholipase and arginine ester hydrolase which are known to be heat stable enzymes $(2,3)$. The inhibitor also contains a hemorrhagic activity which is lost after heating. In SDSpolyacrylamide gel electrophoresis, the inhibitor, even after heating, shows one protein band. Thus it has been unsettled whether the heat stable component included in the drugmetabolizing enzyme inhibitor shows biological activity other than drug-metabolizing enzyme inhibitory action. The present study was conducted to clarify the biological activity of the heat stable component included in the inhibitor.

\section{Materials and Methods}

Materials: Habu venom used in this study was a pool of lyophilized venom taken from specimens of Habu (Trimeresurus flavoviridis) collected on Okinawa Island in 1978. Sephadex G-100 (Particle size: 40-120 nm) was parchased from Pharmacia Fine Chemicals (Uppsala, Sweden). Amberlite CG-50 (type II) was obtained from the Rohm \& Hass Co. (Philadelphia, PA). PTosyl-L-arginine methyl ester hydrochloride was obtained from Nakarai Chemicals Ltd. (Kyoto). All other regents were of analytical grade.

Methods: The venom fraction with drugmetabolizing enzyme inhibitory action was isolated by the same method as described in the previous report (1) except that the fraction with drug-metabolizing enzyme inhibitory action eluted from the Amberlite CG50 column was chromatographed twice 
on the column with a linear gradient of 0.2 to $0.3 \mathrm{M}$ sodium chloride in $0.005 \mathrm{M}$ borate$\mathrm{HCl}$ buffer $(\mathrm{pH}$ 8.3). The isolated fraction with drug-metabolizing enzyme inhibitory action was heated at $70^{\circ} \mathrm{C}$ for $5 \mathrm{~min}$, and the supernatant after centrifugation at $3000 \mathrm{rpm}$ for $15 \mathrm{~min}$ was used as the heat stable component. Venom fractions were dialyzed against isotonic sodium chloride solution before measurement of biological activity. Hemorrhagic activity was measured by the method of Kondo et al. (4). Vascular permeability of the venom fraction was observed with rabbits. Evans Blue $(20 \mathrm{mg}$ in $1 \mathrm{ml}$ of isotonic sodium chloride solution) was given into ear vein of a rabbit followed by an intracutaneous injection of $0.1 \mathrm{ml}$ venom fraction into depilated back skin. The rabbit was killed with ether $2 \mathrm{hr}$ after the venom injection, and the skin was removed. Blue spots caused by injection of venom fractions were observed from the visceral side of the removed skin. Smooth muscle contractive action was examined with the ileum removed from guinea pig according to the method of Ishida et al. (5). Unless mentioned, the ileum preparation was changed in every experiment because of tachphylaxis caused by repeated use. The effect of the isolated venom fraction on blood coagulation was studied by measuring the time for fibrin formation with citrated blood. Five $\mathrm{ml}$ of blood taken from the jugular vein of a dog under anesthesia with pentobarbital was added into the test tube containing $0.5 \mathrm{ml}$ of $3.8 \%$ sodium citrate. The resultant supernatant of citrated blood after centrifugation at $3000 \mathrm{rpm}$ for 15 min was allowed to settle in a water bath at $37^{\circ} \mathrm{C}$ for $10 \mathrm{~min}$. The venom fraction $(0.2$ $\mathrm{ml}$ ) of varing concentrations was mixed with $1.0 \mathrm{ml}$ of citrated blood followed by addition of $0.5 \mathrm{ml}$ of $0.025 \mathrm{M}$ calcium chloride solution. Coagulant activity was measured by examining fibrin formation of the blood mixture. In the whole blood, the venom fraction of $0.1 \mathrm{ml}$ was mixed with $1.0 \mathrm{ml}$ of fresh blood, and the clotting time was measured. Isotonic sodium chloride solution was used as the control instead of the venom fraction. The activity of phospholipase, proteinase or arginine ester hydrolase was measured according to the method described in the previous report (1). Protein concentration of the venom fraction was measured by the method of Lowry et al. (6). Aminopyrine $\mathrm{N}$-demethylase activity was measured as described in the previous report (1).

\section{Results}

The venom fraction with drug-metabolizing enzyme inhibitory action (RRCG50) was $1.7 \%$ of the crude venom, and one-fourth of the fraction was heat stable (HRRCG50). Before and after heating, the fraction showed one protein band on SDS-polyacrylamide gel electrophoresis with a molecular weight of 27,500. Both phospholipase and arginine ester hydrolase activities were not detected in the inhibitory fraction, while proteinase activity was scarcely observed. The fraction decreased aminopyrine $\mathrm{N}$-demethylase activity to $60 \%$ in vivo.

Figures 1 and 2 showed the effect of the inhibitor on vascular permeability and hemorrhage. The inhibitor caused hemorrhage and increase of vascular permeability, but these effects of the venom were completely lost after heating.

The coagulation times of citrated blood after addition of 6-7 $\% \mathrm{~g}$ of heated crude $\mathrm{Habu}$ venom, nonheated, and heated purified drugmetabolizing enzyme inhibitor were 15, 22 and $26 \mathrm{~min}$, respectively, while the control time by adding isotonic sodium chloride

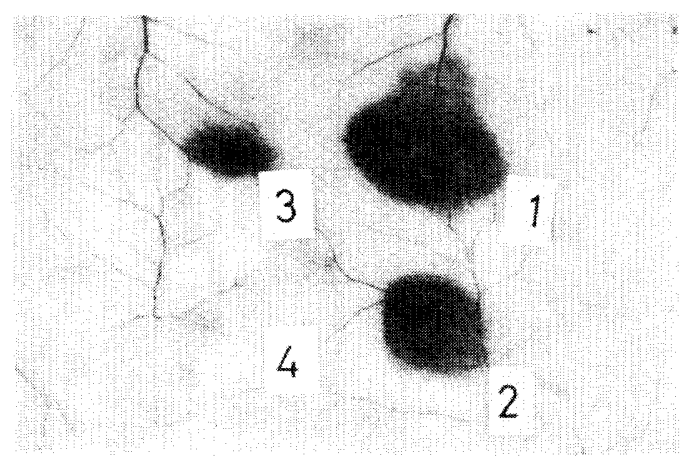

Fig. 1. Hemorrhagic activity. Purified venom fraction (RRCG50) or the heated fraction (HRRCG50) was injected intracutaneously to rabbits, and hemorrhagic activity was measured as described in Materials and Methods. 1: RRCG50 (60 $\mu \mathrm{g} / 0.1 \mathrm{ml})$. 2: 1/4 RRCG50, 3: 1/10 RRCG50, 4: HRRCG50 $(15 \mu \mathrm{g} / 0.1 \mathrm{ml})$. 
solution was 3 min (Table 1). The coagulation time of the blood after treatment with heat

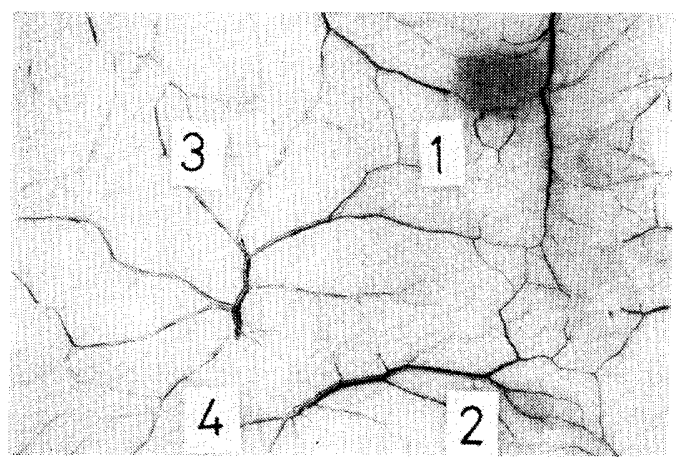

Fig. 2. Vascular permeability. Purified venom fraction ( $R R C G 50$ ) or the heated fraction (HRRCG50) was injected to rabbits and vascular permeability was measured as described in Materials and Methods. 1: RRCG50 (60 $\mu \mathrm{g} / 0.1 \mathrm{ml}), 2: 1 / 10$ RRCG50, 3: HRRCG50 (15 $\mu \mathrm{g} / 0.1 \mathrm{ml}), 4$ : isotonic sodium chloride solution $(0.1 \mathrm{ml})$.

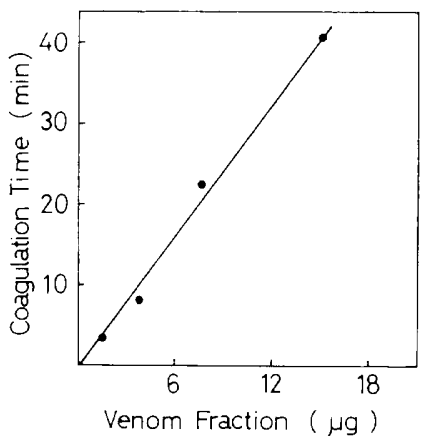

Fig. 3. Effect of heated venom fraction on coagulation of citrated blood. Each dose of the heated fraction (HRRCG50) was added to citrated blood. and the time for fibrin formation was measured as described in Materials and Methods. stable component was delayed dosedependently as shown in Fig. 3. This means that the drug-metabolizing enzyme inhibitor, including the heat stable component of the fraction, possesses the inhibitory action on blood coagulation.

The effect of the inhibitor on smooth muscle was examined with guinea pig ileum. As shown in Figs. 4 and 5, the drugmetabolizing enzyme inhibitor contracted the ileum muscle. Addition of 110 to $150 \mu \mathrm{g}$ per $\mathrm{ml}$ of the inhibitor caused the ileum contraction, but a repeated treatment with the inhibitor caused tachyphylaxis. The contractive effect of the inhibitor was decreased by treatment with atropine and increased with physostigmine. The heat stable component included in the inhibitor also contracted the muscle, as shown in Fig. 6, and

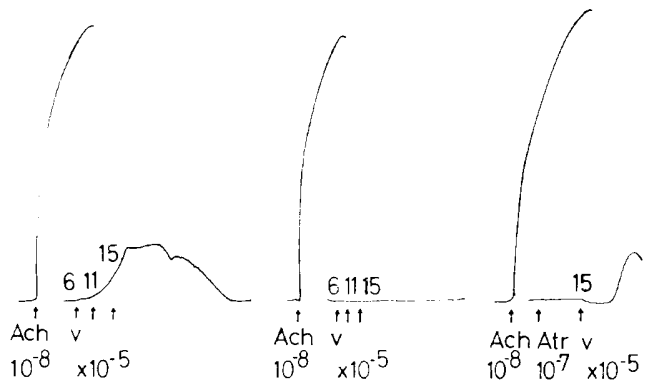

Fig. 4. Action of purified fraction (RRCG50) on the isolated guinea pig ileum. Ileum contraction was measured as described in Materials and Methods. The venom fraction (RRCG50) was added cumulatively into the bath (left figure), and after washing of the ileum with Tyrode solution, the venom was again given by the same method (center figure). ACh: $10^{-8} \mathrm{~g} / \mathrm{ml}$ acetylcholine, Atr: $10^{-7} \mathrm{~g} / \mathrm{ml}$ atropine, $V: 6,11,15 \times 10^{-5} \mathrm{~g} / \mathrm{ml}$ RRCG60.

Table 1. Anticoagulant activity of venom fractions

\begin{tabular}{|c|c|c|c|c|c|c|c|}
\hline & \multicolumn{5}{|c|}{ Coagulation time (min) } & & \\
\hline & \multirow[t]{2}{*}{ Control } & \multicolumn{2}{|c|}{$\begin{array}{l}\text { Crude venom } \\
\text { (heated) }\end{array}$} & \multicolumn{2}{|c|}{ RRCG50 } & \multicolumn{2}{|c|}{ HRRCG50 } \\
\hline & & $7 \mu \mathrm{g}$ & $14 \mu \mathrm{g}$ & $6 \mu \mathrm{g}$ & $60 \mu g$ & $7 \mu \mathrm{g}$ & $15 \mu \mathrm{g}$ \\
\hline Whole blood & 10 & & & & 27 & & 14 \\
\hline Citrated blood & 3 & 15 & $>60$ & 22 & $>60$ & 26 & 44 \\
\hline
\end{tabular}

Venom fraction was mixed wih blood, and the clotting time was measured as described in Materials and Methods. RRCG50: purified venom fraction. HRRCG50: heated purified venom fraction. 


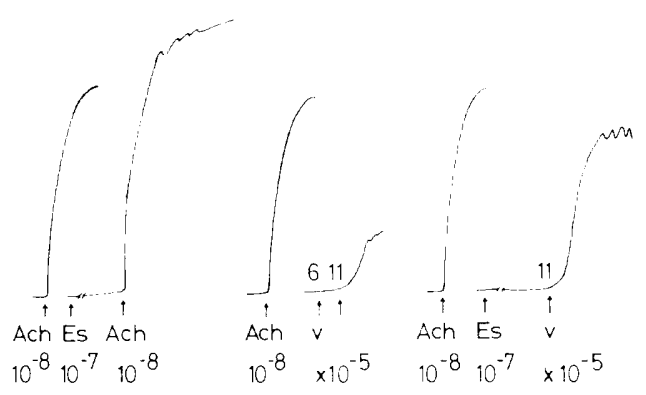

Fig. 5. Action of purified fraction (RRCG50) on the isolated guinea pig ileum in the presence of physostigmine. Ach: $10^{-8} \mathrm{~g} / \mathrm{ml}$ acetylcholine. Es: $10^{-7} \mathrm{~g} / \mathrm{ml}$ physostigmine, $v: 6,11 \times 10^{-5} \mathrm{~g} / \mathrm{ml}$ RRCG50.

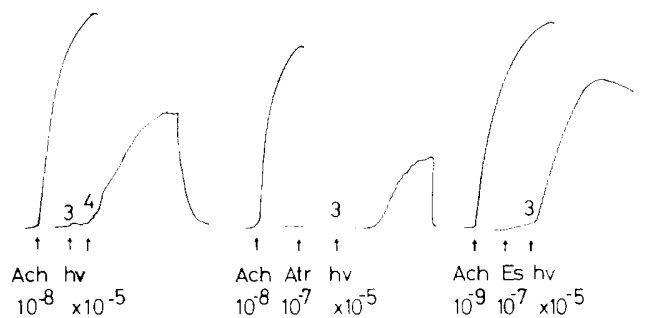

Fig. 6. Action of heated fraction (HRRCG50) on the isolated guinea pig ileum. Ach: $10^{-8} \mathrm{~g} / \mathrm{ml}$ acetylcholine, Es: $10^{-7} \mathrm{~g} / \mathrm{ml}$ physostigmine, Atr: $10^{-7} \mathrm{~g} / \mathrm{ml}$ atropine, hv: $3,4 \times 10^{-5} \mathrm{~g} / \mathrm{ml} \mathrm{HRRCG50}$.

the action of the heat stable component was inhibited or potentiated by treatment with atropine or physostigmine as well as nonheated inhibitor.

\section{Discussion}

Drug-metabolizing enzyme inhibitor separated from Habu venom was similar to hemorrhagic principle 2 ( $\left.\begin{array}{ll}H R & 2)\end{array}\right)$ in the aspects of hemorrhagic activity, molecular weight, and a lack of other enzymatic activities such as phospholipase and proteinase (7). However, Ohsaka (8) proposed that purified hemorrhagic principle did not have blood coagulant inhibitory action. Since he did not present detailed data about anticoagulant activity of the venom, it is difficult to compare his fraction with our fraction. This discrepancy may come in part from the difference of purification steps that we used. Amberlite CG-50 as cation ion exchanger while Ohsaka preferred Bio-Rex 70 , and also from the difference of venom source since we used the venom from Habu collected from Okinawa Island whereas he collected the venom from Amami Ohshima Island. The heat stable component containing the inhibitory activity was one-fourth of the whole protein, and it was not separated by column chromatography. Though the heated crude venom anticoagulant activity was not so strong, this may be due to involvement of the component with coagulant activity, thrombin like enzyme (3, 9), which was separated from the drug-metabolizing enzyme inhibitory fraction (data not shown). It is reasonable that hemorrhagic and anticoagulant activities are included in the same fraction of the Habu venom, and the latter may aggravate hemorrhage by inhibition of hemostasis.

Anticoagulant principle has been separated from the snake venom of Agkistrodon acutus, Trimeresurus gramineus, and $T$. mucrosguamatus (10-12). The former two of them are acidic glycoproteins, and the last one is phospholipase A. The drugmetabolizing enzyme inhibitory fraction from Habu venom was a basic protein, and it had no phospholipase A activity. It is, therefore, clear that the fraction with anticoagulant activity isolated from the Habu venom is different from that of the other three venoms. Further studies to clarify the mechanism of anticoagulant activity of the Habu venom fraction are in progress.

The drug-metabolizing enzyme inhibitor from the Habu venom contracted guinea pig ileum, and the heat stable component included in the inhibitor also had the same effect on the smooth muscle. This contraction of guinea pig ileum by the inhibitor, also by the heat stable component, was decreased with atropine and was potentiated with physostigmine. Thus it was suggested that the contraction of the ileum was due to an acetylcholine-like substance which might be released by the venom treatment. Atropine did not completely inhibit the ileum contraction: therefore, other pharmacological mediators may be involved in the smooth muscle contraction. According to Ishida et al. (5), hemorrhagic principle causes an ileum 
contraction which may involve pharmacological mediators such as acetylcholine, histamine and slow reacting substances. It is likely that the same mediators as reported by Ishida et al. (5) may be responsible for the present contraction. Components with low molecular weight in the venom may not be involved in the pharmacological effect caused by purified venom fraction because these components were removed through purification steps such as gel filtration or dialysis. Moreover, the heat stable component included in the drug-metabolizing enzyme inhibitor was demonstrated to be a protein (1).

Thus, it was clarified in this study that the heat stable protein included in the drugmetabolizing enzyme inhibitor from Habu venom showed smooth muscle contraction of guinea pig ileum and anticoagulant activity on citrated blood.

Acknowlegements: Habu venom was a kind gift from the Okinawa Prefectural Institute of Public Health. This work was supported in part by a Grant-in Aid for Scientific Research from the Ministry of Education, Science and Culture, Japan (No 56570082).

\section{References}

1 Aniya, Y. and Matsusaki, K.: Inhibition of hepatic microsomal drug-metabolizing enzymes by Habu snake (Trimeresurus flavoviridis) venom fractions. Biochem. Pharmacol. 31, 2039-2046 (1982)

2 Kihara, H.: Studies on phospholipase $A$ in Trimeresurus flavoviridis venom. 11. Purification and some properties of phospholipase A. Japan. J. Trop. Med. Hyg. 2, 27-34 (1974)

3 Aniya, $Y$. and Matsusaki, K.: Arginine ester hydrolase of the venom of Habu. Trimeresurus flavoviridis (Hallowell). Ryukyu Univ. J. Health Sci. Med. 2, 124-130 (1979) (in Japanese)

4 Kondo, H., Kondo, S., Ikezawa, H., Murata, R. and Ohsaka, A.: Studies on the quantitative method for determination of hemorrhagic activity of Habu snake venom. Japan. J. Med. Sci. Biol. 13, 43-51 (1960)

5 Ishida, Y., Yamashita, S., Ohsaka, A., Takahashi, T. and Omori-Satoh, T.: Pharmacological studies of the hemorrhagic principles isolated from the venom of Trimeresurus flavoviridis, a Crotalid. In Animal, Plant, and Microbial Toxins, Edited by Ohsaka, A., Hayashi, K. and Sawai, Y., Vol. 2, p. 263-271. Plenum Publishing Corporation, New York (1976)

6 Lowry, O.H., Rosebrough, N.J., Farr, A.L. and Randall, R.J.: Protein measurement with the Folin phenol reagent. J. Biol. Chem. 193, 265275 (1951)

7 Takahashi, T. and Ohsaka, A.: Purification and some properties of two hemorrhagic principles (HR2a and HR2b) in the venom of Trimeresurus flavoviridis; complete separation of the principles from proteolytic activity. Biochim. Biophys. Acta 207, 65-75 (1970)

8 Ohsaka, A.: Biochemical aspect of increased vascular permeability for proteins and erythrocytes with special reference to the mechanism of hemorrhage. J. Japan. Biochem. Soc. 48, 308-331 (1976) (in Japanese)

9 Denson, K.W.E., Russell, F.E., Almagro, D. and Bishop, R.C.: Characterization of the coagulant activity of some snake venoms. Toxicon 10 , 557-562 (1972)

10 Ouyang, C. and Teng, C.M.: Purification and properties of the anticoagulant principle of Agkistrodon acutus venom. Biochim. Biophys. Acta 278, 155-162 (1972)

11 Ouyang, C. and Yang, F.: Purification and properties of the anticoagulant principle of Trimeresurus gramineus venom. Biochim. Biophys. Acta 386, 479-492 (1975)

12 Ouyang, C., Teng, C., Chen, Y. and Lin, S.: Purification and characterization of the anticoagulant principle of Trimeresurus mucrosquamatus venom. Biochim. Biophys. Acta 541, 394 407 (1978) 